\title{
Overview of The Sustainable Technology System about Rural Residential Construction
}

\author{
Yuan Ling ${ }^{1}$, Liu Xiaohui ${ }^{1}$, Wang lisha ${ }^{1}$, and Huang Xianming ${ }^{1}$ \\ ${ }^{1}$ Architectural Design and Research Institute of Tsinghua University Co., LTD, Chaoyang District, China
}

\begin{abstract}
This paper is based on the national key R\&D project of China during the 13th Five-Year Plan- "Research On The Construction Technology System of Green Livable Rural Residential Buildings" (2018YFD1100205). Based on the quantitative analysis and systematic sorting of the research journals on sustainable rural residential construction, this paper summarizes the research progress and development trend of sustainable rural residential construction, analyzes the basic characteristics and common problems of rural residential construction in China at present, and proposes a sustainable construction strategy and research system according to local conditions.
\end{abstract}

\section{Relevant research and practice}

The main content of this paper is the sustainable technology of rural residential construction. We summarized the relevant researches on China and established the research framework, so as to provide a foundation for further research.

\subsection{Literature analysis}

The Research before 2012 focused on the overall rural construction in China, such as earthquake relief and new rural construction, natural disasters and policies have strong guidance. After 2013, the research focus has gradually been put into specific technologies, especially energy saving technologies, including thermal performance of building envelope, renewable energy utilization, indoor thermal environment and comfort,etc. After 2016, research on rural energy conservation is becoming mature, the latest research hotpots include building construction mode, main structure of building (including prefabricated building, industrialized building), function space, etc([1]).

In China, the research of building science on rural residence is relatively extensive, among which indoor thermal environment, energy saving, building envelope structure, flat planning design, solar energy and prefabricated building are the main concerns. The research on the construction technology of rural residential buildings mainly includes two aspects: the overall strategy and specific technologies, the research of energy saving and thermal environment-related technology takes the largest proportion in the specific technology research, and they are mainly concentrated in the super-cold zone and cold zone where the envelope is the key factor of energy saving.
Compared with the research in China, the international studies mainly in western developed countries has little research in the main structure and prefabricated building of rural residence, they pay more attention to the comfort of the built environment, sustainability, landscape ecology, the protection and renewal of rural cultural heritage. And the thermal performance of building envelope, indoor physical environment, pollution emissions and renewable energy utilization are also concerned internationally.

\subsection{Other studies}

By extracting the important scientific research and demonstration projects of rural residence in China in the past 20 years, and sorting them out according to the climate zone and time sequence, we found that the research focuses mainly concentrated in the plane optimization design, thermal performance of building envelope, improvement of local building materials, solar energy, heating system optimization,etc. And light steel structure system has been widely used in demonstration projects([2,3]). In south of China, the improvement of local building materials and structures, the inheritance of traditional architectural features and techniques, natural ventilation, reconstruction of existing buildings, and spontaneous construction are the main features of the research([4,5]).

\section{Summary of problems}

Based on the literature research and the demonstration projects, we summarizes the current construction characteristics of rural residence as follows:

- $\quad$ The living mode of rural residence is based on agricultural activities, and the function space is more 
diverse and complex than the living space in the city. Agricultural production, storage and even transportation all takes up part of the space of the farmhouse.

- $\quad$ The activities of village residents are open, most activities of villagers are outdoors, especially in the courtyards. Courtyards play an important role in rural life. Compared with indoor space, the use frequency of courtyard is higher and the function is more complex.

- $\quad$ As the homestead is owned by villagers, it will be built and expanded independently according to the changes of their family structure, economic level and lifestyle. In the long-term life, the use mode of the house is constantly changing along with the major life events such as "son marriage" and " have children ", people and environment influence each other to achieve a dynamic equilibrium([6]).

- $\quad$ Compared with the city, the regionality of rural residence is more obvious. The rural self-built houses in different regions have formed unique regional features under restrictions of population density, climate, topography, economic development level and other conditions. For example, through the investigation of self-built houses, Zhou Xiaohong([7]) and others found that the houses are mainly single-storey in north China, while those in the southern of Qinling Mountains-huaihe River are mostly multi-storey buildings.

- At present, China's rural aging problem is widespread. Most of the young and middle-aged workers choose to go out to work, while most of the old and children stay in the village. According to the analysis of the sixth census data([8]), the proportion of the elderly over 65 years old in villages and towns was 60.06 percent of the total population. Yao Yao([9]) made a survey of self-built houses in Anhua and found that 69 percent of the households have elderly people, and the elderly's intention is to provide for the aged at home. Therefore, the research on suitable aging of rural houses is also one of the main problems in sustainable village construction.

\section{The technology system of rural residential construction}

At present, most of the research on rural residential construction in China is aimed at specific content. Such as the safety of structural system, the energy-saving effect of building envelope, or the introduction of demonstration projects in specific areas and their applied technologies. There are few studies on the whole building system and the whole country. Which can be referred to is the research that studied by Liu Fang et al([10]), they proposed a technology system of well-off residential housing in villages and towns. However, since this system was put forward in 2015, which were introduced emphatically were the hotspot at that time, such as the energy-saving, new energy utilization and disaster prevention. After nearly 5 years of development, energy-saving, new energy and disaster prevention technology have become the normal design, which do not need separate chapter. Therefore, on the basis of referring to the above system, this paper proposes a concise framework for sustainable housing combining with the current construction characteristics, as shown in the following figure:

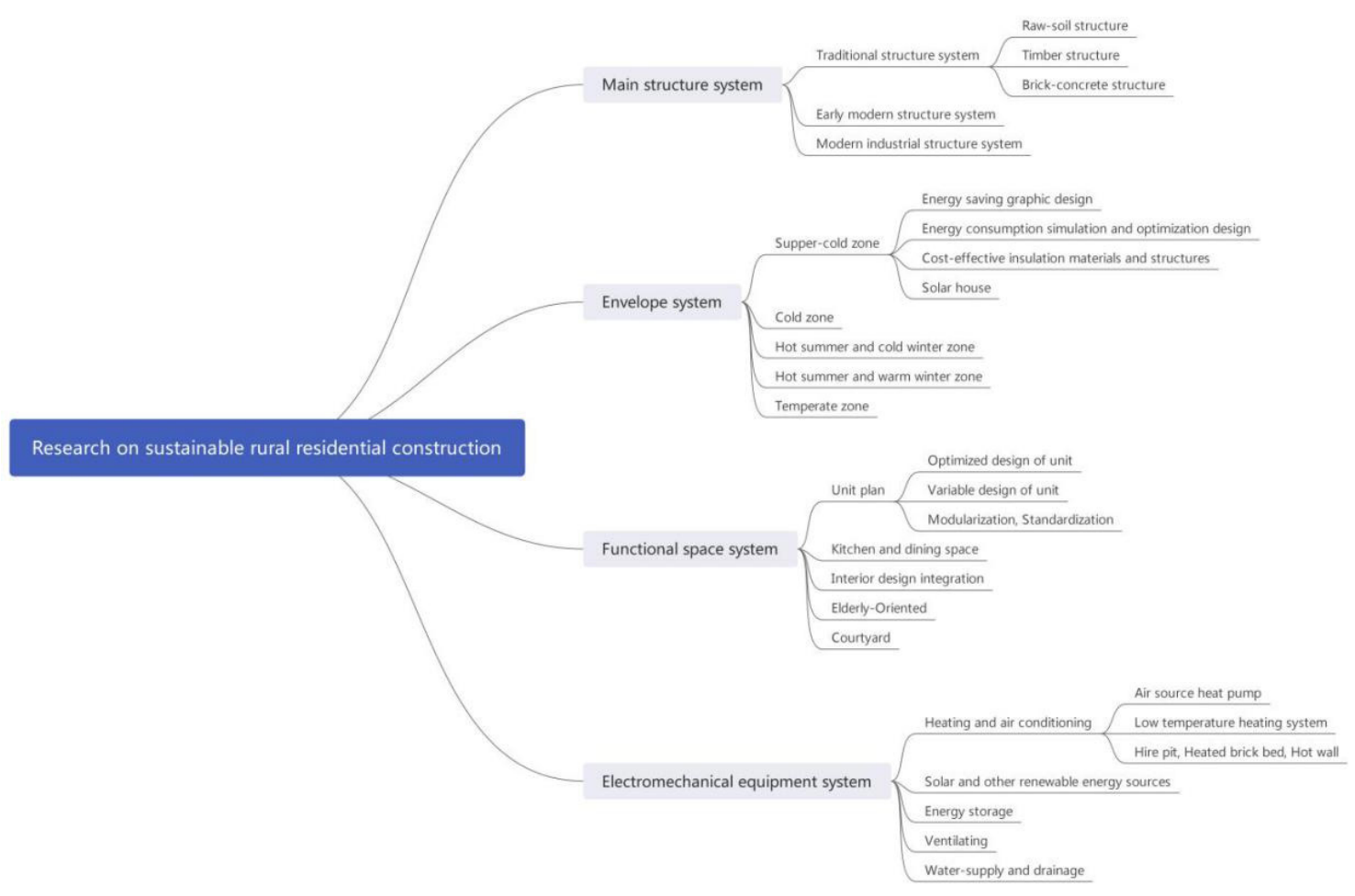

Fig. 1. Research framework for sustainable rural residence 
The construction research system consists of three levels. The first level is classified according to the basic components of architecture, the second part is the key content of each basic component of architecture, and the last level is specific sustainable technologies.

\subsection{The main structure of buildings}

In recent years, more and more studies have been conducted on the residential structural system of villages and towns in China. The research contents most concentrated on the hot spots such as prefabricated building and industrialized building. In addition, Due to low price and low technical requirements, the traditional raw soil structure and brick-concrete structure still occupy a large proportion of use in villages and towns. Therefore, many scholars and designers are carrying out optimization research on the traditional system([11,12]). Based on the current research results, the author believes that the co-development of multiple structural forms is still the main trend in China in the near future. As long as the principle of adapting to local conditions is satisfied, various structural forms can be used as sustainable construction techniques.

Chinese traditional structure system includes raw soil structure, stone structure, timber structure and so on. The raw soil structure adopts adobe, lime or rammed earth to form load-bearing walls. It is characterized by the convenience of materials and construction, low cost, good heat preservation and fire resistance. The disadvantage is that the strength of raw soil structure is low and the structural integrity is poor, which is suitable for the areas with abundant raw soil resources. The stone structure system adopts stone block as load-bearing wall, which has similar advantages to raw soil structure and better weather resistance than raw soil structure. The disadvantages are no seismic structural measures, poor tensile strength and structural integrity of materials. Stone structure system is suitable for areas where is rich in stone resources. The timber structure is mainly loaded by timber, characterized by light weight, good earthquake resistance, rapid construction and ecological. But the fire resistance, insect control and anticorrosion ability of timber is poor. The use of timber structure is restricted by timber resources, which is more suitable for areas rich in timber resources.

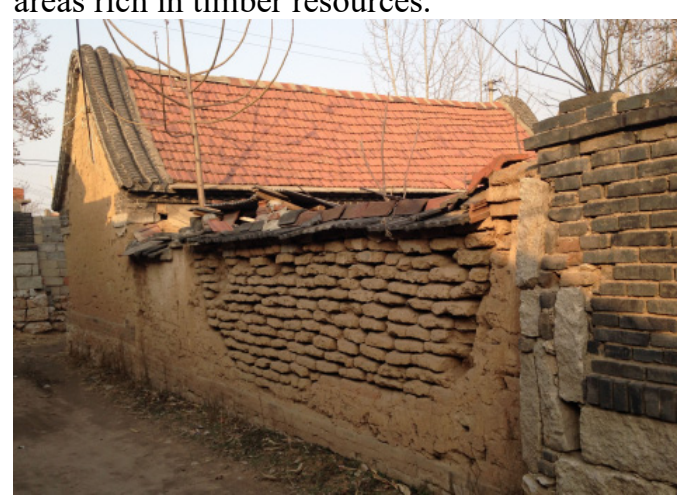

Fig. 2. Raw soil structure([13])
Picture source:Wang Y, research on the sustainability development of traditional village planning and raw soil construction in yimeng mountain area.

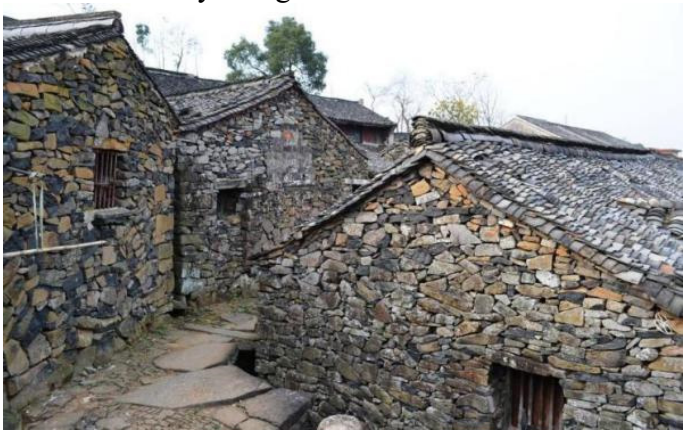

Fig. 3. Stone structure

Picture source: Baidu pictures

The early modern structure system includes brick-wood structure, brick-concrete structure and cast-in-situ concrete structure. The vertical load-bearing wall and column of brick wood structure are brick masonry, and the floor slab and roof truss are made of wood. It is characterized by simple construction technology, low cost, flexible space separation, poor earthquake resistance and poor durability. It is suitable for areas with relatively rich wood resources and low seismic requirements. It should be noted that clay bricks are banned in China and should be replaced by recycled bricks. In brick-concrete structures, reinforced concrete is used on vertical load-bearing walls, constructional columns, floor slabs and roof panels. It is characterized by simple construction technology, low cost, good durability and high structure weight. The disadvantages are poor earthquake resistance, waste of resources and pollution of environmental. It is suitable for areas with low seismic requirements, and it is also necessary to pay attention to the problem that clay bricks need to be replaced by recycled bricks. Cast-in-situ concrete structures bear loads though cast-in-situ concrete. The advantages are simple construction technology, low cost and good comprehensive performance. The disadvantages are high labor cost, waste of resources and pollution of the environment. Cast-in-situ concrete structure is widely used in China at present.

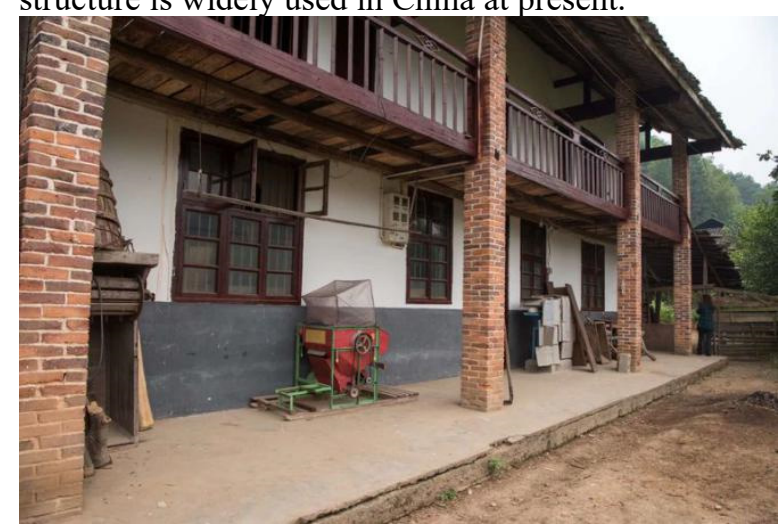

Fig. 4. Brick-wood structure Picture source: Baidu pictures 


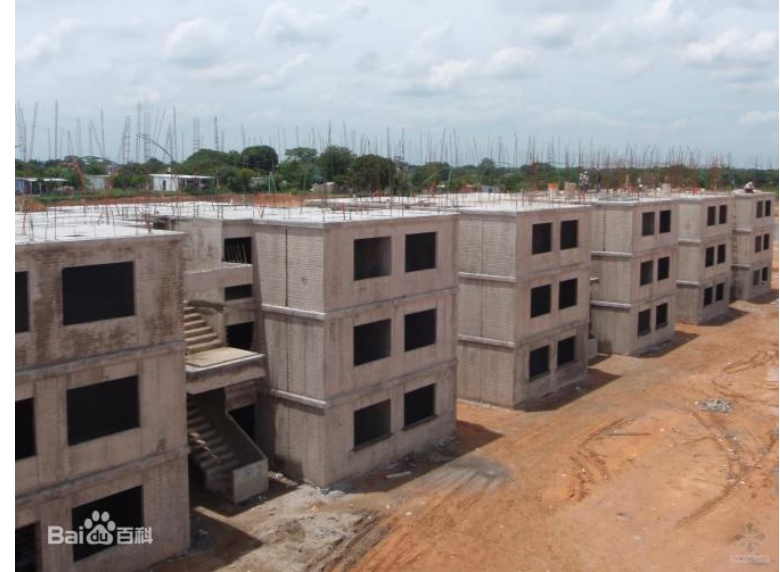

Fig. 5. Cast-in-situ structure

Picture source: Baidu encyclopedia

Modern industrial structure system includes precast concrete structure, steel structure, light steel structure, light timber structure and so on. Precast concrete structure adopts precast components to form the frame or shear wall to bear the load, which has the advantages of good seismic performance, heat preservation, sound insulation and other comprehensive performance. In addition, precast concrete structures perform well in resource intensive utilization and environmental pollution reduction. However, it is expensive to build, requires a higher level of industrial chain and workers' skill, and requires closer system integration. The steel structure system is a frame structure composed of shaped steel components. It adopts plate-type building envelope. The advantages of steel structure are similar to precast concrete, and the structural performance is superior. However, it also has the problem of high cost, high skill requirements for industrial workers, additional requirements for fire prevention and corrosion prevention. In addition, it is difficult to deal with the joints of the structure. Light steel structure is a composite load-bearing system composed of thin-walled light steel material. The advantages and disadvantages are similar to steel structure. These two structural forms are both not widely recognized and accepted. The light timber structure is a composite load-bearing system composed of light timber, with good comprehensive performance and more ecological and environmental protection than steel. But it is expensive and the timber resources need to be imported. Generally speaking, the above-mentioned modern industrial structure system is suitable for regions with relatively developed economy, relevant industrialization foundation, policy and financial support, and good transportation conditions.

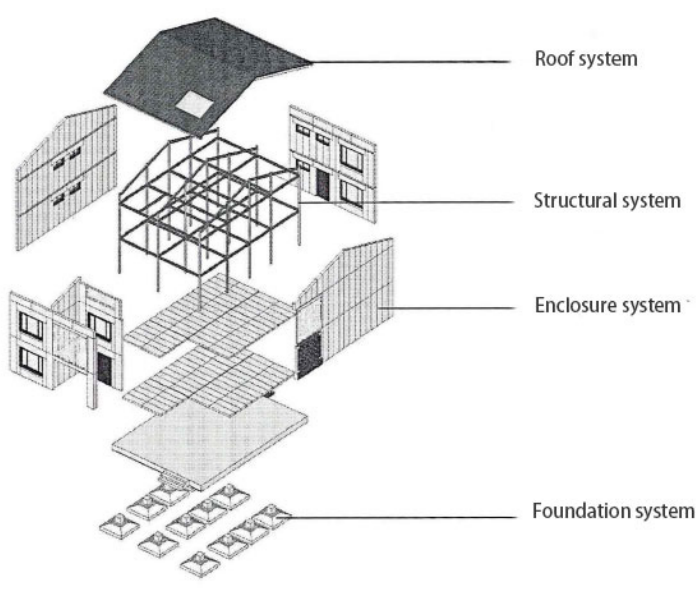

Fig. 6. Steel structure([14])

Picture source: Zhang L, Application discussion of the assembled steel structure in rural housing of severe cold areas.

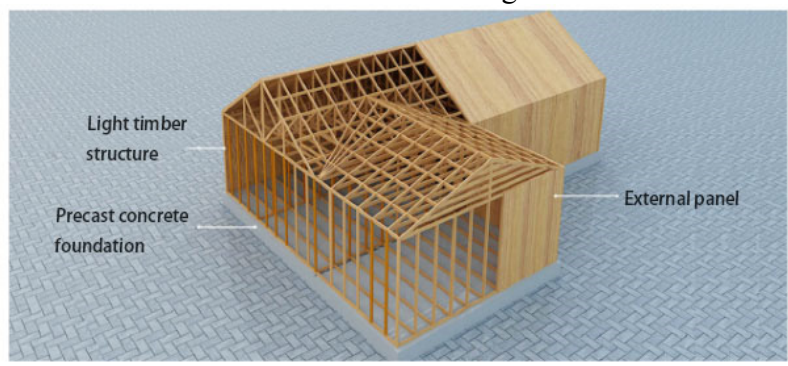

Fig. 7. Light timber structure([15])

Picture source: Wang L X, Study on the design of new wooden structure housing in jilin province.

\subsection{Building envelope}

The study of building envelope is mainly based on the climatic and regional characteristics, it can be summarized according to the climatic zones in China. Supper-cold zone and cold zone have similar research emphasis and suitability technology, but it should be noted that there are some differences between the two regions: most of the supper-cold zone are sparsely populated, with agriculture and animal husbandry as the main industry and rich natural resources, which are suitable for the application of renewable and natural materials such as raw soil, wood and straw. Most of the cold regions have relatively dense population, high degree of industrialization, relatively poor natural resources and great pressure on environmental protection, so it is more suitable to promote the utilization of industrial recycled materials and the improvement of traditional local materials and structures. In temperate zone, the performance requirements of envelope structures are not high, and there are few relevant studies, so there is no in-depth discussion in this paper. 


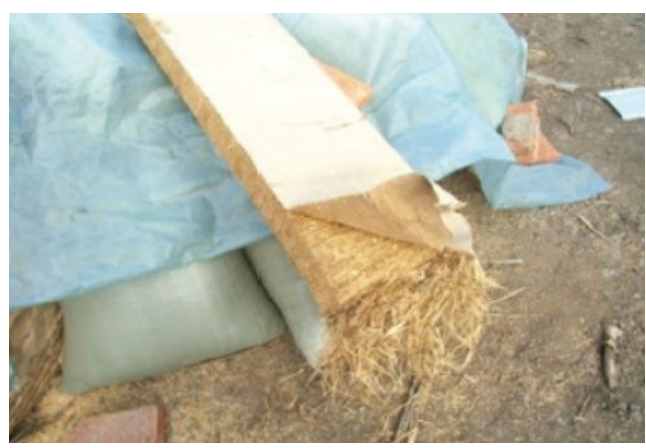

Fig. 8. Compressed straw building slabs([16])

Picture source: Jin H, A study on the construction technics of strawbale walls in severe cold rural areas of northeast China (in

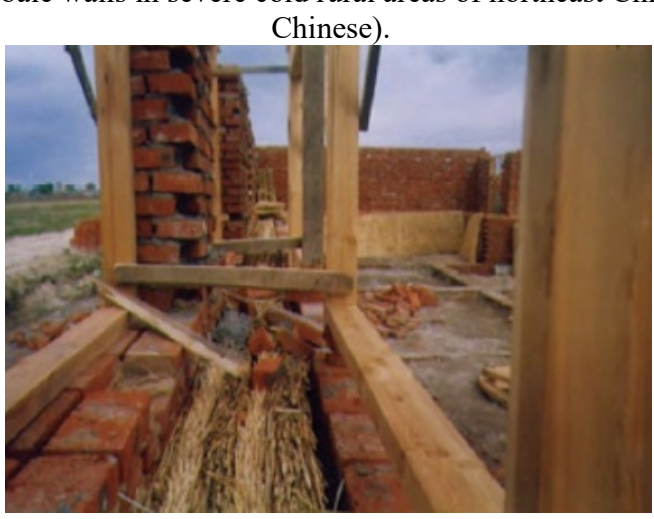

Fig. 9. Sandwich straw composite wall([16])

Picture source: Jin H,A study on the construction technics of strawbale walls in severe cold rural areas of northeast China (in Chinese).

In super-cold zone, the research emphases of building envelope mainly includes: energy saving design, energy saving renovation, thermal performance of materials and structures, indoor thermal comfort, passive technology, (super) low energy consumption technology, and renewable materials. The sustainability technologies of envelope in supper-cold zone mainly include:

- Energy-saving graphic design (system coefficient control, distinguishing heating and cooling areas,etc.);

- Energy consumption simulation and optimization design;

- $\quad$ Cost-effective thermal insulation materials and structures, such as composite insulation blocks, straw brick, thermal insulation curtain, roof composite thermal insulation system,etc;

- $\quad$ Solar house, passive house;

- Application of natural renewable materials.

On the basis of supper-cold zone, the research of heat insulation performance is added in cold zone. The sustainability technologies of envelope in cold zone mainly include:

- Energy consumption simulation and optimization design;

- $\quad$ Cost-effective thermal insulation materials and structures, such as composite insulation blocks, improved raw soil materials, roof composite insulation system, energy-saving doors and windows, etc;

- $\quad$ Solar house, passive house, and passive design combined with greenhouse;
- Industrial recycled materials, integrated insulation structure;

- Improvement of local materials and structures.

Research on building envelope in hot summer and cold winter zone mainly includes: energy-saving design and renovation, heat preservation and insulation performance of envelope structure, moisture-proof design and construction, combination with regional nature, culture and local skills. The sustainability technologies of envelope in hot summer and cold winter zone mainly include:

- $\quad$ Energy consumption, ventilation simulation and optimization design;

- $\quad$ Thermal insulation materials and structures, such as external thermal insulation materials, composite thermal insulation blocks, energy-saving doors and windows, elevated overhead roof;

- $\quad$ The ground moisture-proof and heat insulation composite technology;

- Industrial recycled materials;

- Improvement of local materials and structures.

Research on building envelope structure in hot summer and warm winter zone mainly includes: energy saving design, thermal insulation performance of envelope structure, ventilation, thermal environment and shading,etc. The sustainability technologies of envelope in hot summer and warm winter zone mainly include:

- $\quad$ Energy consumption, ventilation simulation and optimization design;

- $\quad$ Shading of windows;

- $\quad$ Roof and external wall structure;

- Patio ventilation, the pulling air shaft.

\subsection{Function space}

Functional space is the most important part of the whole residential construction research, because the function of the building plays an integral role in the study of other parts. It mainly includes architecture, interior design, landscape and parts design,etc. Based on the quantitative analysis of relevant literature, we divided it into five main fields, namely: unit plans, kitchen and dining room, interior design integration, elderly-oriented and courtyard.

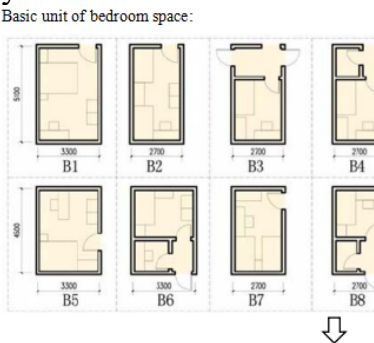

Basic unit of kitchen space:

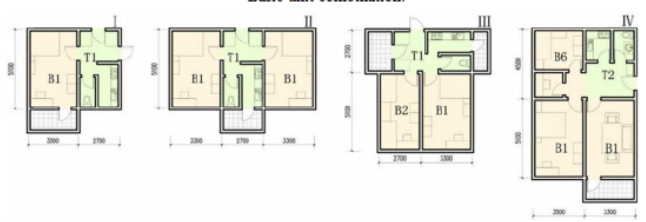

Fig. 10. "Basic room" setting and combination([17]) 
Picture source: Chen T, Layout standardized design and diversity application research of light steel prefabricated rural house.

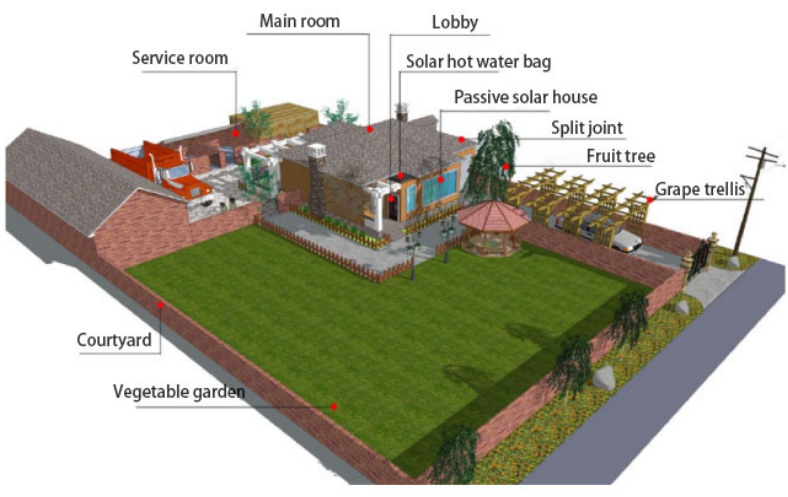

Fig. 11. Example of rural residential graphic design([18]) Picture source: Cong Z C, The research on green mode modeling of northeast rural dwelling.

The research emphases of unit plans are: historical evolution and current situation, demands of modern living, adaptability and variability of whole life cycle, connection between unit plans and industrialization (prefabricated construction). Sustainability research technologies include optimized design of unit plans, variable unit plans design, modular and standardized design. The research focus of kitchen and dining room is traditional customs and living habits, public and family communication space, dynamic line design,etc. Sustainable technologies include integrated design, improved kitchen design, kitchen storage system,etc. The research of the integration of internal assembly is mainly related to the industrialization of internal assembly and system integration. Sustainable suitability technologies include: system integration, integral storage system, overhead floor and wiring system, integral kitchen and bathroom system, furniture system,etc. The research on elderly-oriented focuses on the characteristics and needs of home-based care, the psychological and physiological characteristics of the elderly in rural areas, and the sharing of the elderly and children. Sustainable adaptive technologies include retrofit and design for aging, aging parts,etc. The research about courtyard focuses on the physical environment, use demand and efficiency, land conservation and ecology, courtyard economy,etc. Sustainable adaptive technologies include integrated design, variable design, physical environment comfort, courtyard ecological environment and so on.

\subsection{Equipment and pipeline}

Equipment and pipeline is mainly aimed at HVAC, water supply and drainage, electrical engineering research. Due to the particularity of rural residence, there are few studies on electromechanical engineering. The main contents of equipment and pipeline research include: heating and air conditioning, solar energy and other renewable energy utilization, energy storage, ventilation, water supply and drainage pipeline system,etc.

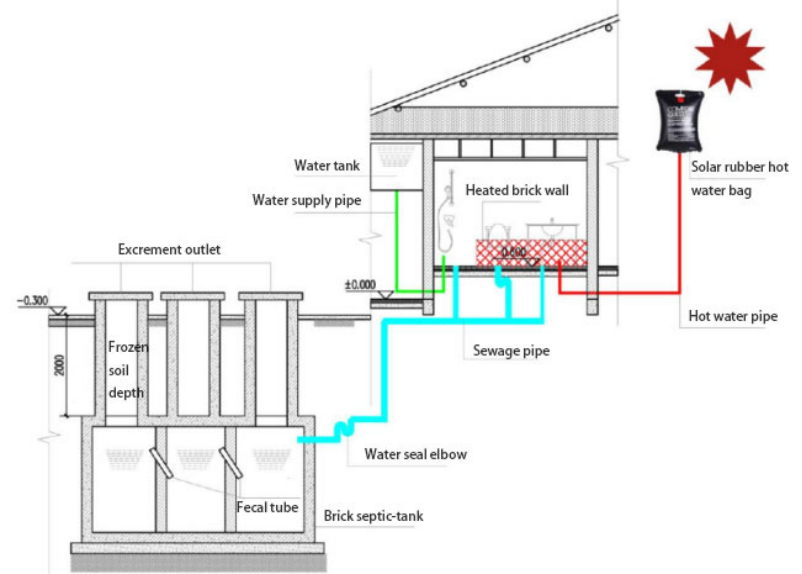

Fig. 12. Example of rural residential toilet equipment([18]) Picture source: Cong Z C, The research on green mode modeling of northeast rural dwelling.

The research emphases of heating and air conditioning mainly include: heating load calculation and simulation, system optimization design, combination and selection of different heat sources and air conditioning terminal, improvement of traditional heating mode. Sustainable suitability technologies include air source heat pump system, low temperature heating system, kang (fire wall) and so on. Solar energy and other renewable energy research focus on solar heating and building integration design. Sustainable technologies include solar heating and hot water utilization, integrated design of buildings, solar energy combined with other heat sources for heating, photo-voltaic power generation and biomass energy. The main research content in the field of energy storage are energy storage materials and components, the combination of energy storage and solar energy. Sustainability technologies include phase change materials and modules, thermal storage floors and walls and other components. Research on water supply and drainage focus on improvement of aqua privy and sewage treatment,etc. Specific technologies include water-saving appliances, pipes for water supply and drainage, rainwater collection and utilization, and utilization of small-scale sewage treatment.

\section{Summary}

The research on "sustainable rural residential construction technology" has a rich foundation. Based on these studies, we propose a technology system and draw up a detailed list of construction technologies. Finally, we summarize the following measures and suggestions:

- According to the general problems, it is necessary to further study the people's different demands for rural residence under different economic development levels, locations and industrial conditions in the next 5-10 years;

- $\quad$ Based on these requirements, to improve and perfect the corresponding construction mode, and form a systematic construction strategy;

- $\quad$ Based on the above summarized technology system, to put forward relevant supporting technical 
standards and key index parameters for construction, and develop the key database for the design and construction of green livable towns and villages;

- It is necessary to pay attention to the protection of traditional villages, rural buildings, historic and cultural villages and towns, so as to maintain regional characteristics;

- The promotion of green technology needs the government's support, and the guidance of national policy plays an important role in the construction of green livable villages and towns.

\section{References}

1. Yuan L, et al. Literature Review of Construction Technologies for Green and Livable Rural Housing. Community,(2019).

2. Jin $\mathrm{H}$, et al. Designing rural houses of low energy consumption and high comfort in response to the extremely cold climate: a case study of an immigrant village in woniuhe town, Zhalantun. Architectural journal, (2015):74-77.

3. An S, The construction and application of the light assembly plate housing system:a case study of the rural house in zoucheng, shandong, Master's thesis of Southeast University,(2017).

4. Zhang S H, Construct new countryside: experience from "New Zhenshan environmental housing project"in Guizhou province, Huazhoong architecture,(2007):63-65.

5. Zhang M Z, Ren W Z, Practice and thinking of sustainable rural construction:a case study on Anji eco-house. Eco-city and green building,(2012):80-85.

6. Li B, Chen C, Form and use of rural house in natural village:a case study of village J in Shanghai Suburb. Architectural journal,(2011):116-120.

7. Zhou X H, Chu B, Research on the usage of living rooms and the configuration of furniture in self-built rural housing. Architectural journal,(2011):12-17.

8. Cai Q, Xiang HL, Analysis on the current situation and development trend of China's rural ageing: Based on the data of the sixth national population census. Journal of hubei polytechnic institute,(2013):99-104.

9. Yao Y, The research on the current situation and the adaptability for the elderly of self-built houses in rural areas of Anhua, Master's thesis of Hunan University,(2018).

10. Liu F, Yi B Y, Technology System Research Approach and Establishment,Applicable in Building Well-off Residential Housing in Villages and Towns. Housing science.(2015):29-32.

11. $\mathrm{Li} \mathrm{W} \mathrm{J,} \mathrm{et} \mathrm{al.} \mathrm{Research} \mathrm{and} \mathrm{ponderation} \mathrm{on} \mathrm{the}$ precast building structure system based on the new rural construction. Structural engineers,(2018):173-178.
12. Zhang P P, Exploration on prefabricated residential buildings in rural development. Master's thesis of Zhe Jiang University,(2018).

13. Wang Y, Research on the sustainability development of traditional village planning and raw soil construction in yimeng mountain area. Chang'an University,(2015).

14. Zhang L, Application discussion of the assembled steel structure in rural housing of severe cold areas. Dalian University of technology,(2017).

15. Wang LX, Study on the design of new wooden structure housing in jilin province. Jilin Jianzhu University,(2018).

16. Jin H, Kang J, Jin $Y$ M, et al. A study on the construction technics of strawbale walls in severe cold rural areas of northeast China (in Chinese). Sci Sin Tech,(2016),46:1079-1085.

17. Chen $\mathrm{T}$, Layout standardized design and diversity application research of light steel prefabricated rural house, Beijing University of technology.

18. Cong Z C, The research on green mode modeling of northeast rural dwelling:Dwellings in heilongjiang province as an example. Xi'an University of architecture and technology,(2014). 